\title{
LETRAMENTOS DIGITAIS: REFLEXÕES ACERCA DOS PROCESSOS DE ENSINO-APRENDIZAGEM
}

\section{DIGITAL LITERACY: REFLECTIONS ON TEACHING-LEARNING PROCESSES}

\author{
Fábio Narduchi de Paula* \\ Alexandre de Jesus Pereira \\ Juliana Narduch de Paula Mansur ${ }^{* * *}$ \\ Joaquim Oliveira
}

\begin{abstract}
Resumo: Diante de uma nova ordem das coisas, em que mídias e tecnologias digitais ocupam, cada vez mais e mais intensamente, um lugar especial nos modos de se viver e de se aprender, urge refletirmos sobre os processos de ensino e aprendizagem diante dos denominados letramentos digitais. Na rede informacional que nos envolve, misturam-se vários saberes e formas muito diversas de se aprender, enquanto nosso sistema educativo ainda se encontra todo organizado em torno da escola e do livro. Em meio à nova sociedade da informação, duas culturas se convergem: professores ("estrangeiros digitais") e alunos ("nativos digitais"), que se defrontam e se confrontam com experiências diversas em relação às tecnologias digitais. O presente estudo, de cunho bibliográfico, visa debater os letramentos digitais para os processos de ensino e aprendizagem, partindo do conceito de letramento de Magda Soares e de profanação de Giorgio Agamben. Esperamos que, nessa era da internet, o professor possa fazer de sua sala de aula um espaço de construções coletivas, de aprendizagens compartilhadas, tendo as Tecnologias Digitais de Informação e Comunicação como pedras angulares desse processo. Logo, a profanação do improfanável é a tarefa política da geração que vem.
\end{abstract}

Palavras-chave: Processos de ensino e aprendizagem. Letramentos digitais. Tecnologias Digitais de Informação e Comunicação. Profanação.

\footnotetext{
"Mestre pelo Programa de Pós-Graduação em Humanidades, Culturas e Artes da UNIGRANRIO. Pósgraduado em Língua Portuguesa e em Supervisão e Orientação Educacional pela Universidade Cidade de São Paulo UNICID. Graduado em Educação Física pela Universidade Estácio de Sá. Atualmente, é docente das prefeituras de Nova Iguaçu e da cidade do Rio de Janeiro.

Graduado em Educação Física pela UNISUAM (2012). Atualmente é Diretor Geral da Prefeitura Municipal de Mesquita.

*** Bacharel em Direito e Licenciada em Letras pela Universidade Estácio de Sá. Professora da Escola municipal Professor Leopoldo Machado.

Doutor em Filosofia pela Pontifícia Universidade Católica do Rio de Janeiro.. Atualmente é professor do Programa de Mestrado e Doutorado Interdisciplinar: Humanidades, Culturas e Artes UNIGRANRIO; professor na Escola de Ciências Sociais e Aplicadas - Curso de Bacharel em Direito e da Escola de Ciências da Saúde - Curso de Psicologia da UNIGRANRIO e professor do Curso de Bacheral em Direito do UNIFESO.
} 
Abstract: Faced with a new order of things, in which digital media and technologies increasingly occupy a special place in the ways of living and learning, it is urgent to reflect on the teaching and learning processes before so-called digital literatures. In the information network that surrounds us, several knowledge and very different forms of learning are mixed, while our educational system is still organized around the school and the book. In the midst of the new information society, two cultures converge: teachers ("digital aliens") and students ("digital natives"), who are confronted with diverse experiences in relation to digital technologies. The present bibliographic study aims to discuss the digital literacy for the teaching and learning processes, starting from the concept of literacy by Magda Soares and the desecration of Giorgio Agamben. We hope that, in this age of the internet, the teacher can make of his classroom a space of collective constructions, of shared learning, with Digital Information and Communication Technologies as the cornerstones of this process. Therefore, the desecration of the unfaithful is the political task of the coming generation.

Key words: Teaching and learning processes. Digital literacy. Digital Information and Communication Technologies. Desecration. 


\section{INTRODUÇÃO}

Magda Soares (2002), ao conceituar letramento, parte do pressuposto de que o termo não se refere às próprias práticas de leitura e escrita, aos eventos relacionados com o uso e com a função dessas práticas ou, até mesmo, ao impacto ou às consequências da escrita sobre a sociedade, mas, para além de tudo isso, ao estado ou à condição daqueles que exercem "as práticas sociais de leitura e de escrita, de quem participa de eventos em que a escrita é parte integrante da interação entre pessoas e do processo de interpretação dessa interação - os eventos de letramento"” (SOARES, 2002, p. 145, grifos da autora).

Letramento digital é entendido, por sua vez, como "um certo estado ou condição que adquirem os que se apropriam da nova tecnologia digital e exercem práticas de leitura e de escrita na tela, diferente do estado ou condição - do letramento - dos que exercem práticas de leitura e de escrita no papel." (SOARES, 2002, p. 151, grifos da autora).

Vivemos, na contemporaneidade, um grande paradoxo, sobretudo, um grande desafio: a escola encontra-se assentada no que Magda Soares (2002, p. 143) afirma ser a "cultura do papel", em meio a uma "cultura da tela, ou cibercultura". Assim, diante de uma "nova ordem das coisas" (FREITAS, 2010, p. 341), em que mídias e tecnologias digitais ocupam, cada vez mais e mais intensamente, um lugar especial nos modos de se viver e de se aprender, urge refletirmos sobre os processos de ensino e aprendizagem diante dos famigerados letramentos digitais ${ }^{2}$.

Em meio à "nova sociedade da informação", "era da informática" ou, até mesmo, "era da internet" (FREITAS, 2010, p. 349) ${ }^{3}$, duas culturas se convergem: "professores ('estrangeiros digitais') e alunos ('nativos digitais'), que se defrontam e se confrontam com experiências diversas em relação às tecnologias digitais."

\footnotetext{
1 "Um evento de letramento é qualquer situação em que um portador qualquer de escrita é parte integrante da natureza das interações entre os participantes e de seus processos de interpretação" (SOARES, 2002, p. 145).

2 O termo letramentos digitais encontra-se pluralizado corroborando a assertiva de Soares (2002, p. 156) de que diferentes efeitos cognitivos, culturais e sociais são engendrados "em função ora dos contextos de interação com a palavra escrita, ora em função de variadas e múltiplas formas de interação com o mundo - não só a palavra escrita, mas também a comunicação visual, auditiva, espacial.".

${ }^{3}$ Kenski (2012, p. 23) afirma-nos, inclusive, que: "Alguns autores contemporâneos falam até que estamos vivendo em plena 'sociedade tecnológica'”.
} 
Saviani (2008, p. 73) já nos adverte para o fato de que "a educação é um ato político", isto é, "contém uma dimensão política", de modo que "a importância política da educação reside na sua função de socialização do conhecimento. É realizandose na especificidade que the é própria que a educação cumpre sua função política." Assim, "a educação, sendo uma relação que se trava fundamentalmente entre nãoantagônicos, supõe a união e tende a se situar na perspectiva da universalidade." (SAVIANI, 2008 p. 70).

No entanto, no que tange à sua função de socialização do conhecimento entre não antagônicos, isto é, entre professores e alunos, supondo, assim, a união entre ambos, conforme nos afirma Saviani (2008) ao nos referir à dimensão política da educação, ressaltamos que, "na rede informacional que nos envolve, misturam-se vários saberes e formas muito diversas de aprender, enquanto nosso sistema educativo ainda se encontra todo organizado em torno da escola e do livro.", (FREITAS, 2010, p. 341). Diante desse desafio, "muitas vezes os docentes adotam uma posição defensiva e às vezes até negativa, no que se refere às mídias e às tecnologias digitais, como se pudessem deter seu impacto e afirmar o lugar da escola e o seu como detentores do saber." (FREITAS, 2010, p. 341).

Esse estudo busca refletir acerca dos letramentos digitais para os processos de ensino e aprendizagem, partindo do conceito de profanação de Giorgio Agamben (2007), pois, conforme Lévy (1994), a escola é uma instituição que, há cinco mil anos, baseia-se no falar/ditar do mestre, na escrita manuscrita do aluno e, há quatro séculos, em um uso moderado da impressão, e que a Informática, segundo Lopes (2004), vem adquirindo relevância, cada vez maior, no cenário educacional.

\section{A PROFANAÇÃO DO IMPROFANÁVEL}

Tendo por base o trabalho de Dede (1992), Hugo Assmann (1993) afirma que a Educação se revelou, entre todas as instituições da sociedade, a mais estável, de modo que, se um habitante da América do século XVIII fosse transportado para dois séculos mais tarde, acabaria por achar desnorteadora a maior parte das organizações modernas, porém reconheceria, instantaneamente, os métodos de ensino e grande parte do equipamento instrucional que caracterizam a 
educação nas escolas, visto que, conforme ele, uma série de fatores organizacionais e contextuais tornou as abordagens tradicionais do ensino praticamente impenetráveis no que se refere a mudanças. Urge, portanto, uma reflexão nesse sentido, levada a cabo neste artigo, a fim de se romper com práticas petrificadas no cotidiano escolar, mormente, nos processos de ensino e aprendizagem.

Giorgio Agamben (2007) convida a profanar, ou seja, a restituir ao uso o que estava consagrado, isto é, indisponível e separado, inalcançado, desativando, assim, os dispositivos de poder e devolvendo ao uso comum os espaços que o modelo sagrado (consagrado) havia confiscado. Sendo assim, o filósofo diz ser possível que o Improfanável, sobre o qual se funda a "religião capitalista", no sentido de que o capitalismo institui modos de ser no mundo consagrados, institucionalizados, tal qual a religião, não seja, de fato, improfanável e que, atualmente, ainda haja formas eficazes e também possíveis de profanação ${ }^{4}$.

$\mathrm{Na}$ natureza, segundo o filósofo, também acontecem profanações, como ocorre com o gato que brinca com um novelo como se fosse um rato, usando, conscientemente, de forma gratuita, os comportamentos próprios da atividade predatória, exatamente como a criança fazia com antigos símbolos religiosos ou com objetos que pertenciam à esfera econômica, próprios, respectivamente, do culto religioso ou do mundo do trabalho (AGAMBEM, 2007).

Analogamente, ressaltamos e propugnamos que a escola, particularmente os processos de ensino e aprendizagem, não deva permanecer centrada no falar/ditar do mestre, na escrita manuscrita do aluno e em um uso moderado da impressão (LÉVY, 1994), em meio à relevância, cada vez maior, da Informática no cenário educacional e, consequentemente, de sua importância nesse contexto (LOPES, 2004).

A cultura escolar não deve mais permanecer fechada em seus métodos de ensino e aprendizagem historicamente instituídos, fugindo de uma realidade, cada vez mais, existente: o uso das tecnologias digitais e da Internet, que "têm impulsionado mudanças na educação e resultado na necessidade de

\footnotetext{
${ }^{4}$ A despeito de o capitalismo, levando ao extremo uma tendência já presente no cristianismo, generalizar e absolutizar, em todo âmbito, a estrutura da separação que define a religião, por intermédio do paradigma da impossibilidade de usar, ou melhor, da impossibilidade de fazer uso de outras formas de se viver não consagradas. (AGAMBEM, 2007)
} 
profissionalização de professores para o uso de ambientes virtuais, em uma nova cultura escolar." (BERALDO; MACIEL, 2016, p. 209).

Soares (2002, p. 147) enfatiza, inclusive, o "processo em andamento, na cibercultura $^{5}$, de desenvolvimento de novas práticas digitais de leitura e de escrita, em confronto e contraposição com as já tradicionais práticas sociais quirográficas e tipográficas de leitura e de escrita."

As Tecnologias Digitais de Informação e Comunicação (TDIC) (Joly, Silva, \& Almeida, 2012; Scorsolini-Comin, 2014), como ferramentas mediadoras em atividades sociais permitem aos indivíduos participarem de múltiplos contextos de desenvolvimento social e cognitivo, sejam eles de aprendizagens formais ou informais.

Expor e discutir as mudanças advindas da virtualização do corpo, dos objetos e dos espaços de interação (Lévy, 1996) exige negociações de significados que são construídos em um novo fazer coletivo e requer novas formas de pensar a educação. (BERALDO; MACIEL, 2016, p. 2010).

Assim sendo, tendo em vista a "interconexão mundial de computadores", ou melhor, “a extensão do ciberespaço ${ }^{6}$ [...] em ritmo acelerado" (LÉVY, 1999, p. 24), a Internet é encarada, dentro dessa lógica, "como uma rede que congrega diversas pessoas, grupos, que mantêm relações entre si." (SOBRINHO, 2014, p. 121), o que encontra eco em Castells (2003), que esclarece que o uso da internet aumenta a sociabilidade a distância e na comunidade local.

De acordo com Araujo e Vilaça (2016, p. 28, grifos dos autores): "Acessamos a internet dos smartphones, tablets, notebooks, entre outros dispositivos. Em outras palavras, podemos levar a internet conosco.", de modo que: "Fazendo um pequeno jogo de palavras: saímos de casa, saímos com a internet e não saímos da internet.".

\footnotetext{
${ }^{5}$ Cultura Digital ou Cibercultura consiste, segundo Lévy (1999, p.17), no "conjunto de técnicas (materiais e intelectuais), de práticas, de atitudes, de modo de pensamento e de valores que se desenvolvem juntamente com o crescimento do ciberespaço.".

${ }^{6}$ Ciberespaço é definido por Lévy (1999, p. 92, grifo do autor) "como o espaço de comunicação aberto pela interconexão mundial dos computadores e das memórias dos computadores". Além do mais, constitui-se no "novo meio de comunicação que surge da interconexão mundial de computadores. O termo especifica não apenas a infra-estrutura material da comunicação digital, mas também o universo oceânico de informações que ela abriga, assim como os seres humanos que navegam e alimentam esse universo." (LÉVY, 1999, p.17).
} 
Nessa direção, Fantin e Rivoltella (2012, p. 97, grifo dos autores) afirmam: "A cultura digital é também uma cultura em que a portabilidade [...] é o item mais importante.", de modo que "a tecnologia vira uma roupa, sem a qual é difícil sair de casa.". Ademais, "Os aparelhos [...] estão cada vez mais potentes. Com eles é possível fazer muitas coisas: conectar-se, comunicar-se, editar textos e imagens.".

Diante de tal panorama, ressaltamos e reiteramos a importância e a necessidade do uso das TDIC nos processos de ensino e aprendizagem, como recursos pedagógicos ao auxílio de professores, de modo que "os professores devem ser letrados digitais", precisando, pois, "conhecer os gêneros discursivos e linguagens digitais que são usados pelos alunos, para integrá-los, de forma criativa e construtiva, ao cotidiano escolar." (FREITAS, 2010, p. 340) ${ }^{7}$.

Celulares, notebooks, softwares de edição de imagem e som, câmeras de vídeo, GPS, iPads conectados à rede, por exemplo, são recursos potenciais que podem ser integrados em atividades de iniciação científica a partir de dados da Internet, mecanismos de busca, ferramentas de visualização ou plataformas de aprendizagem na produção coletiva (Beraldo \& Barbato, 2013; Versuti, Beraldo, \& Gosciola, 2014). As escolas estão repletas das TDCl introduzidas formalmente através de projetos do governo ou secretarias de educação e, informalmente, pelos estudantes e professores quando usam seus dispositivos digitais. Desse modo, que sentido tem manter os estudantes enfileirados com notebooks ou tablets de última geração sem aproveitar pedagogicamente o potencial das redes? $O$ que falta para incluir as TDIC na sala de aula? (BERALDO; MACIEL, 2016, p. 210, grifo da autora).

Freitas (2010, p. 340) afirma que "precisamos, portanto, de professores e alunos que sejam letrados digitais, isto é, professores e alunos que se apropriam crítica e criativamente da tecnologia, dando-Ihe significados e funções, em vez de consumi-la passivamente.", de modo que: "O esperado é que o letramento digital seja compreendido para além de um uso meramente instrumental.". Nesse sentido, "observamos a necessidade de profissionalização do professor para o uso de ambientes virtuais, recursos abertos e elaboração de planos de aulas mais conexos com as potencialidades das TDIC." (BERALDO; MACIEL, 2016, p. 210).

\footnotetext{
${ }^{7}$ Os Parâmetros Curriculares Nacionais da Língua Portuguesa (BRASIL, 1998) postulam, inclusive, como objetivos do Ensino Fundamental, que os alunos sejam capazes de: "saber utilizar diferentes fontes de informação e recursos tecnológicos para adquirir e construir conhecimentos;" (BRASIL, 1998, p. 8).
} 
Nessa direção, oportuno mencionar, Beraldo e Maciel (2016, p. 210, grifo da autora) destacam projetos experimentais que, segundo eles, "apresentaram bons resultados", como é o caso do "Educomunicação pelas Ondas do Rádio [...], em que professores e alunos utilizam o rádio e computadores para projetos integrados às práticas curriculares.", do "Mídias e Tecnologias Educacionais Livres", no qual "professores e alunos compartilham objetos por simulação, jogos, vídeos, áudio e conteúdo.", do "projeto audiovisual Programa Intervalo, que vai ao ar pela TV Educativa da Bahia (TVE/Canal 2) em que os estudantes são os próprios protagonistas de várias temáticas contemporâneas (www.educacao.ba.gov.br/intervalo)". Tais projetos são, segundo as autoras,

iniciativas locais e com gestão compartilhada - entre coordenadores, professores e alunos -, a partir de uma demanda que surge de circunstâncias geradas na comunidade escolar, pois o que fazem juntos tem sentido e a 'melhor' tecnologia tem um aspecto relacional com as vivências do cotidiano. (BERALDO; MACIEL, 2016, p. 210).

Freitas (2010, p. 341) pontua que, "na rede informacional que nos envolve, misturam-se vários saberes e formas muito diversas de aprender, enquanto nosso sistema educativo ainda se encontra todo organizado em torno da escola e do livro.". Assim sendo, dentro do contexto de profanar o Improfanável (AGAMBEN, 2007), e, tendo em vista a escola como instituição baseada e fundamentada, historicamente, no falar/ditar do mestre, na escrita manuscrita do aluno e no uso moderado da impressão, é imprescindível que a imagem e o som possam tornar-se pontos de apoio de novas tecnologias intelectuais (LÉVY, 1994).

Dentro dessa perspectiva de rompimento com práticas petrificadas no cotidiano escolar, ou melhor, de profanar práticas historicamente instituídas (AGAMBEN, 2007), Beraldo e Maciel (2016, p. 211) ${ }^{8}$ apontam exemplos de quando as TDIC são introduzidas em disciplinas, tais como em "atividades colaborativas em que professores e estudantes podem fazer visitas virtuais intercaladas por pesquisa de campo a oceanários, museus, casas de cultura, planetários ou projetos de preservação", além do uso dessas tecnologias para uma videoconferência, por exemplo, de maneira que "a sala de aula possa estar conectada em qualquer ponto

\footnotetext{
${ }^{8}$ Apoiando-se em Beraldo e Barbato (2013).
} 
do planeta, onde um pesquisador, autor de livro, especialista em determinada área ou até estudantes de outras escolas, podem discutir temas relativos ao conteúdo da disciplina.".

Em pesquisa com grupo de professores, Freitas (2010) aponta o entusiasmo e o interesse, por parte desses docentes, em relação aos trabalhos que desenvolvem com seus alunos, utilizando a plataforma Moodle, como também a satisfação encontrada, pelas experiências obtidas, ao trabalharem com fóruns de discussão e outros recursos dessa plataforma.

Foi muito interessante observar o consenso da posição dos participantes quanto ao papel da escrita na internet. Na realidade, foi apontado que o computador e a internet oferecem uma pluralidade de espaços e de meios que poderiam levar a novas formas de aprendizagem, como o som, a imagem, o movimento, a animação, o vídeo, etc. (FREITAS, 2010, p. 343).

Soares (2002) mostra que a escrita, na tela, possibilita a criação de um texto, fundamentalmente, diferente do texto no papel, o chamado hipertexto, que é, conforme Lévy (1999, p. 56), "um texto móvel, caleidoscópico, que apresenta suas facetas, gira, dobra-se e desdobra-se à vontade frente ao leitor".

O hipertexto é, assim, diferentemente do texto no papel, escrito e lido de maneira multilinear, multi-sequencial, "acionando-se links ou nós que vão trazendo telas numa multiplicidade de possibilidades, sem que haja uma ordem predefinida.", conforme aponta Soares (2002, p. 150), tendo, pois,

a dimensão que o leitor lhe der: seu começo é ali onde o leitor escolhe, com um clique, a primeira tela, termina quando o leitor fecha, com um clique, uma tela, ao dar-se por satisfeito ou considerar-se suficientemente informado - enquanto a página é uma unidade estrutural, a tela é uma unidade temporal. (SOARES, 2002, p. 150)

Em suma, podemos dizer que "a tela, como novo espaço de escrita, traz significativas mudanças nas formas de interação entre escritor e leitor, entre escritor e texto, entre leitor e texto e até mesmo, mais amplamente, entre o ser humano e o conhecimento.", de acordo com Soares (2002, p. 151), tendo consequências sociais, cognitivas e discursivas, configurando, assim, um letramento digital. 
Há quem defenda que os processos envolvidos nesse letramento digital reaproximam o ser humano de seus esquemas mentais, com uma forma de leitura e de escrita que mais se aproximam de nosso próprio esquema mental, de nosso pensamento, que se dá por associações, em rede, como é o caso de autores como Ramal (2002) e Bolter (1991), que defendem tal posição. Outros, tal como Chartier (1994, p. 100), defendem que "a representação eletrônica dos textos modifica totalmente a sua condição", de maneira que "essas mutações comandam, inevitavelmente, imperativamente, novas maneiras de ler, novas relações com a escrita, novas técnicas intelectuais." (1994, p. 101). Dessa forma, a tela, como espaço de escrita e de leitura,

\begin{abstract}
traz não apenas novas formas de acesso à informação, mas também novos processos cognitivos, novas formas de conhecimento, novas maneiras de ler e de escrever, enfim, um novo letramento, isto é, um novo estado ou condição para aqueles que exercem práticas de escrita e de leitura na tela. (SOARES, 2002, p. 152)
\end{abstract}

Isso levanta questões que, para nós, são de capital importância, que ensejam, portanto, possibilidades de reflexão. E, nessa direção, defendemos "O professor como aprendente e seu novo papel no processo de aprendizagem a partir da construção de um letramento digital, como um conhecimento necessário", tal como em Freitas (2010, p. 343). Todavia, a autora assinala, observando os dados da pesquisa por ela apresentados, a "ausência de disciplinas focalizando a temática dos usos do computador-internet na prática pedagógica.", de maneira que, nos currículos das licenciaturas em Língua Portuguesa, por exemplo, isto é, "do total de disciplinas relacionadas aos conhecimentos específicos para a docência, 2,4\% se referem aos saberes ligados à tecnologia." (FREITAS, 2010, p. 345-6), o que revela, por seu turno, "como a formação inicial de professores ainda está distante de enfrentar computador e internet como instrumentos de aprendizagem.”.

Dessa forma, assinalamos que "o futuro professor não está sendo capacitado para utilizar, em sua docência, os recursos do computador-internet.", não havendo preocupação com o letramento digital desse professor em formação, tal como aponta Freitas, o que acaba por revelar "a distância entre o letramento digital 
dos alunos ['nativos digitais'] e o que lhes é oferecido, sob esse aspecto, em seu processo de formação nas instituições." (FREITAS, 2010, p. 347).

\section{CONSIDERAÇÕES FINAIS}

Concordamos com Beraldo e Maciel (2016, p. 215) quando dizem que "a escola tem um papel efetivo como instrumento desencadeador de desenvolvimento e conhecimento humano.", em contextos mediados pelas TDIC, e que "As novas formas de ensino e aprendizagem exigem posturas mais abertas, dialógicas e emancipatórias.", sendo "indispensável descentralizar os saberes diante de uma escola 'sem paredes'.".

Hoje, conforme aponta Freitas (2010, p. 348 , grifo da autora), "o aluno traz para a escola o que descobriu em suas navegações de internauta e está disposto a discutir com seus colegas e com o professor.", não vendo mais, como outrora, "o professor como um transmissor ou a principal fonte de conhecimento, mas espera que ele se apresente como um orientador das discussões travadas em sala de aula ou mesmo nos ambientes on-line integrados às atividades escolares.".

Nessa perspectiva, "aprender e ensinar utilizando o aparato tecnológico requer a reflexão dos professores para assumirem um novo papel no processo de ensino aprendizagem, o que envolve uma mudança pessoal e cultural.", conforme assinalam Beraldo e Maciel (2016, p. 215), haja vista o fato de "que estamos na terceira geração de nativos digitais.", isto é, de "Estudantes [que] vão à escola para se socializar, para viver a cultura, aprender uns com os outros, expressar emoções, criar vínculos e relações afetivas para se desenvolver."

A possibilidade de pesquisar, ler e conhecer sobre os mais variados assuntos navegando na internet confere ao aluno um novo perfil de estudante, que exige também novo perfil de professor. Cabe ao professor estar atento a essa nova fonte de informações para transformá-las, junto com os alunos, em conhecimento. Essa é uma das características do letramento digital: associar informações, ter uma perspectiva crítica diante delas, transformando-as em conhecimento. O professor é parte inerente e

\footnotetext{
${ }^{9}$ Reiterando as postulações de Beraldo e Maciel (2016) de que as escolas estão repletas das TDCI, formalmente introduzidas por meio de projetos do governo ou de secretarias de educação e, informalmente, por estudantes e professores quando utilizam seus dispositivos digitais, com as quais concordamos.
} 
necessária a todo esse processo, em seu lugar insubstituível de mediador e problematizador do conhecimento, um professor que também aprende com o aluno. (FREITAS, 2010, p. 349)

Assim, conforme a perspectiva lançada por Agamben (2007), a criação de um novo uso para o que esteja consagrado só é possível ao homem se ele desativar o velho uso, tornando-o inoperante. Nesse sentido, "a tarefa das escolas e dos processos educativos é desenvolver novas formas de ensinar e aprender, em razão das exigências postas pela contemporaneidade.", haja vista o fato de que "A revolução tecnológica introduz não só uma quantidade enorme de novas máquinas, mas principalmente um novo modo de relação entre os processos simbólicos que constituem o cultural.", tal como apontado por Freitas (2010, p. 340).

Esperamos, tal como Freitas (2010, p. 349), "que, nessa era da internet, o professor possa fazer de sua sala de aula um espaço de construções coletivas, de aprendizagens compartilhadas.". Logo, "A profanação do improfanável é a tarefa política da geração que vem.” (AGAMBEN, 2007, p. 79).

\section{REFERÊNCIAS}

AGAMBEN, Giorgio. Elogio da profanação. In: AGAMBEN, Giorgio. Profanações. Trad. de Selvino José Assman. São Paulo: Boitempo, 2007.

ARAUJO, E. V. F.; VILAÇA, M. L. C. Sociedade conectada: tecnologia, cidadania e infoinclusão. In: VILAÇA, M. L. C.; ARAUJO, E. V. F. (Org.) Tecnologia, sociedade e educação na era digital. Duque de Caxias, RJ: UNIGRANRIO, 2016.

ASSMANN, H. Paradigmas educacionais e corporeidade. Piracicaba: Editora da Universidade Metodista de Piracicaba (Unimep), 1993.

BERALDO, R. M. F.; MACIEL, D. A. Competências do professor no uso das TDIC e de ambientes virtuais. Revista Psicologia Educacional e Escolar, v. 20, n. 2, p. 209-217, maio/agosto de 2016.

BOLTER, J. D. Writing space: the computer, hypertext, and the history of writing. Hillsdale, NJ: Lawrence Erlbaum Associates, 1991.

BRASIL. Secretaria de Educação Fundamental. Parâmetros curriculares nacionais: terceiro e quarto ciclos do ensino fundamental: língua portuguesa/ Secretaria de Educação Fundamental. - Brasília: MEC/SEF, 1998. 
CASTELLS, M. A galáxia da internet: Reflexões sobre a internet, os negócios e a sociedade. Rio de Janeiro: Zahar, 2003.

CHARTIER, R. Do códex à tela: as trajetórias do escrito. In: CHARTIER, R. A ordem dos livros: leitores, autores e bibliotecas na Europa entre os séculos XIV e XVIII. Brasília, DF: UnB, 1994.

FANTIN, M.; RIVOLTELLA, P. C. (Org.). Cultura digital e formação de professores: usos da mídia, práticas culturais e desafios educativos. In: Cultura Digital e Escola: pesquisa e formação de professores. Campinas, SP: Papirus, 2012.

FREITAS, M. T. A. Letramento digital e formação de professores. Educação em Revista, Belo Horizonte, v. 26, n. 03, p. 335-352, dez. 2010.

KENSKI, V. M. Educação e tecnologias: o novo ritmo da informação. 8.ed. Campinas, SP: Papirus, 2012.

LÉVY, P. As Tecnologias da Inteligência: O Futuro do Pensamento na Era da Informática. 34 ed. Rio de Janeiro: Nova Fronteira, 1994.

LÉVY, P. Cibercultura. São Paulo: Ed. 34, 1999.

LOPES, J. J. A Introdução da Informática no Ambiente Escolar. 2004. Disponível em: <http:// clubedoprofessor.com.br/artigos/artigojunio.pdf>. Acesso em: $17 \mathrm{dez}$. 2017. Artigo enviado ao Clube do Professor em 23 de fevereiro de 2004.

RAMAL, A. C. Educação na cibercultura: hipertextualidade, leitura, escrita e aprendizagem. Porto Alegre: Artmed, 2002.

SAVIANI, D. Escola e democracia. Campinas, SP: Autores Associados, 2008.

SOARES, M. Novas práticas de leitura e escrita: letramento na cibercultura.

Educação e Sociedade, Campinas, v. 23, n. 81, p. 143-160, dez. 2002.

SOBRINHO, P. J. "Meu selfie": a representação do corpo na rede social Facebook. Artefactum: Revista de estudos em Linguagens e Tecnologias, Rio de Janeiro, v.8, n.1, p.120-133, 2014. 